\title{
A Survey on Identifying and Addressing Business Analysis Problems
}

\author{
Aleksander JARZĘBOWICZ* Piotr MARCINIAK ${ }^{\dagger}$
}

\begin{abstract}
Despite the growing body of knowledge on requirements engineering and business analysis, these areas of software project are still considered problematic. The paper focuses on problems reported by business analysts and on applicability of available business analysis techniques as solutions to such problems. A unified set of techniques was developed on the basis of 3 industrial standards associated with IIBA, REQB and IREB certification schemes. A group of 8 business analysts was surveyed to list problems they encounter in their work and to assess their frequency. Selected problems were further analyzed and most suitable techniques were proposed to address them. These proposals were validated through follow-up discussions with business analysts. The main results of research reported in this paper are: the comparative analysis of techniques included in IIBA, REQB and IREB standards and the list of problems reported by practitioners associated with techniques suggested as effective solutions.
\end{abstract}

Keywords: requirements engineering, business analysis, certification schemes, industrial standards, survey, business analysis techniques, requirements problems.

\section{Introduction}

Since the software crisis in 1960s, requirements engineering (RE) is recognized as one of the crucial aspects of software projects. Also currently, requirements engineering and business analysis (BA, understood as a broader term, which encompasses more activities) strongly influence project's results. The post-mortem reviews of software project failures and the reasons behind them reveal that RE/BA issues are among top factors contributing to project success or failure [4][37].

The importance of this subject is widely recognized, which can be confirmed by published standards and books, presence among topics of software engineering conferences and a growing number of certification schemes (and certificates issued) for RE/BA practitioners.

* Department of Software Engineering, Faculty of Electronics, Telecommunications and Informatics, Gdańsk University of Technology, Gdańsk, Poland, e-mail: olek@eti.pg.edu.pl

† Active Code Piotr Marciniak, Gdańsk, Poland, e-mail: chm.pm@hotmail.com 
As the research reported in this paper concerns Polish software industry, we would like to focus more on the local context. The recognition of RE/BA is also visible in Poland and a trend of growing interest can be noticed. Dedicated job positions of "business analyst", "system analyst" or similar are becoming more common. The available certification paths are becoming more popular (partially thanks to Polish versions of training materials). A significant number of training courses is offered - some dedicated to particular certification exams, while others more general, based on several sources. Another sign of interest are the recently published books entirely dedicated to requirements, either being (promptly) translated from international publications [40] or written by Polish authors [6][43].

As a result, many sources of knowledge about RE/BA became available and numerous techniques dedicated to requirements elicitation, analysis, specification and validation are described in the literature. On the other hand, RE/BA is still perceived as a difficult and error-prone part of software projects and the problems related to e.g. cooperation with stakeholders, changing requirements or scope creep are quite common. Therefore, the issue we would like to address is: how well do available RE/BA techniques address the problems encountered by the business analysts in their everyday work. For this purpose we planned and conducted a research study involving industry practitioners.

In our research we intended to answer the questions about: (1) RE/BA techniques described in established sources recognized by the industry; (2) problems affecting RE/BA activities in current software projects; (3) applicability of RE/BA techniques as solutions to most frequent identified problems. We used document analysis approach to answer the first question and survey to address the remaining ones. Due to selection of participants, the survey was limited to Polish IT industry and only business analyst's perception of RE/BA problems and possible solutions to them was identified.

The main contributions of this paper include:

- A comparative analysis of 3 industry standards with respect to the main process areas and to particular RE/BA techniques recommended;

- A list of problems encountered in RE/BA and their frequency scores, gathered in a survey involving business analysts;

- A cross-reference list associating RE/BA problems with potential techniques to address them.

The research study described here was conducted mainly in the second half of 2015. In 2016 its results were presented at the XVIII KKIO Software Engineering Conference (held on September 15-17, 2016 in Wrocław, Poland) and published as conference paper [27]. This paper is an extended version of [27] and provides the following additional contributions: (1) a wider review of related work; (2) outline of processes and areas defined in IREB, REQB and BABOK sources; (3) comparison results for requirements analysis and requirements validation techniques recommended by sources; (4) a full list of RE/BA problems, which were further analyzed to propose solutions to them; (5) solution proposals for each of these problems (both before and after validation); (6) additional examples of validation interviews; (7) a separate section discussing validity issues.

The rest of this paper is organized as follows. Section 2 presents the related work. Section 3 describes the research study and its particular steps: development of a unified set of RE/BA techniques (3.1), an industrial survey aimed at identification of problems (3.2), proposals of techniques to address particular problems (3.3) and validation by interviews 
with business analysts (3.4). Section 4 presents validity threats discussion. Section 5 summarizes our conclusions and outlines possible directions of future work.

\section{Related Work}

Our research included: identifying frequent problems encountered in RE/BA activities, analyzing state of the art RE/BA techniques and selecting the techniques which provide solutions to particular problems. Two main areas of related work to review are: surveying the industry about RE/BA related problems and comparing RE/BA techniques.

A number of surveys (based on questionnaires or interviews) about requirements engineering in the industry are available, but most of them focus more on learning about processes and practices actually used, while surveys and other research approaches targeting $\mathrm{RE} / \mathrm{BA}$ problems encountered by industry practitioners are reported in only a few sources, which we outline below.

Davey and Parker [7] provide a summary of surveys related to requirements elicitation problems, but it does not cover other RE/BA areas like requirements analysis or validation. Similarly, Sethia and Pillai [35], who conducted a wide Systematic Literature Review to identify requirements elicitation problems (as well as their causes and consequences), restrict their study to elicitation area only. A list of most common requirements problems is provided by Firesmith [8], however it is only based on the author's industrial experience, instead of a wider survey. A study based on interviews and focus groups is described by Karlsson et al. [22] - it aims to identify problems (challenges) from various RE/BA areas, but is limited to market-driven software development projects and special challenges stemming from such context.

Solemon et al. [36] describe a survey on problems and practices of the software industry in Malaysia. Liu et al [25] conducted a survey in Chinese companies to determine problems and other contributing factors responsible for projects' failures. Mendez Fernandez et al. [28] who surveyed German and Brazilian software companies, uncovered a number of RE problems, their causes and analyzed differences between those two countries. These three approaches are most similar to our work. Our intention, however, was to study current problems declared by business analysts from Poland and we are not aware of any recent industrial survey research on RE/BA in Polish industry, except [3], which focuses on a single particular problem (hidden requirements anti-pattern).

In the second area of related work (comparing RE/BA techniques) a significant number of available sources can be identified. Most of them focus on techniques for a single particular RE/BA area e.g. requirement elicitation [2][39][41][42], prioritization [38], specification [34] or validation [23][26], some however include a broader scope and intend to cover all areas [5][21][24]. The criteria used for RE/BA techniques comparison include: their inherent characteristics (e.g. ability to represent a given attribute of requirement like priority) [2][5][21][24][26][34][38][39][41][42], applicability context (project size, product type etc.) [21][24][38][41][42] and applicability to known RE problems [21][23]. As result, the only identified source, which addresses a wider scope of techniques and their applicability to address RE problems is [21], which however does not consider RE/BA techniques recently described in industrial standards. As for comparing RE/BA standards, 
the only source known to us is [1], which analyzes contents of BABOK, IREB and SWEBOK but with respect to the general approaches, terms used etc., not the techniques included in each standard.

To summarize: no related work about RE/BA problems in the local context of Polish IT industry nor addressing such problems with RE/BA techniques could be found and, in general, there are not many sources available concerning research on interrelationships between RE/BA problems and techniques.

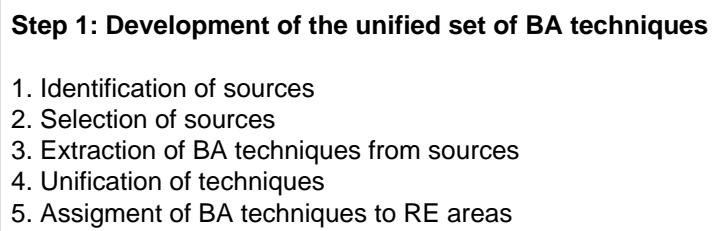

Step 2: Identification of problems by interviewing business analysts

1. Selection and involvement of participants

2. Questioning about problems and collecting answers

3. Processing answers and developing a list of problems

4. Assignment of problems to RE areas

Step 3: Analysis of problems and selection of BA techniques addressing each of them

1. Review of the unified set of BA techniques

2. Selection of techniques best applicable as solutions to each problem

Step 4: Validation through interviews with selected representatives of the group involved in Step 2

1. Statement of the problem

2. Solution proposals issued by interviewee

3. Solution proposals issued by researcher (outcome of Step 3)

4. Discussion and reaching consensus

Figure 1. The overview of the research process

\section{Research Study}

Our research aimed at addressing the following questions: 
- Which RE/BA techniques are recommended by the state-of-the-art sources?

- What problems affecting RE/BA are perceived as most frequent by business analysts?

- Which available techniques are effective in addressing such problems according to business analysts' opinions?

It should be stressed that we sought for the problems from the perspective of business analyst (not e.g. customer) and from the practical viewpoint (real life experiences). As for RE/BA techniques, we decided to focus on areas of requirements development and to exclude requirements management [40]. The research process (shown in Figure 1) was conducted in a number of steps. Each of the steps included several subsequent activities.

\subsection{Step 1 - Development of a Unified Set of Techniques}

The prerequisite to fulfil the aim of step 1 was to identify the candidate sources of knowledge and to choose the basis for further work. At first, we tried the international standards. However, the current main requirements engineering standard (ISO/IEEE 29148:2011 [20]) is not very elaborate with regard to this matter. It lists and briefly summarizes several techniques for e.g. elicitation (page 22) or validation (page 31), but mainly focuses on other issues like requirements engineering process or contents of requirements specification documents. The previous standards (ISO/IEEE 830:1998 [10] and ISO/IEEE 1233:1998 [11]), superseded by 29148, contain even less information about particular techniques.

We turned to certification schemes and associated "industrial standards" instead. We consider them as representative to the present industrial practice - the interest of practitioners is indicated by numbers of certificates issued. According to available stats:

- 31000 professionals in 70 countries received IREB Certified Professional for Requirements Engineering (Foundation Level) certificate [18];

- Until 3rd quarter of 2015, 13570 professionals worldwide obtained REQB certificates [33];

- In a single year (2015), 6400 professionals obtained Certified Business Analysis Professional certificate [13];

Another advantage is the fact that syllabi/examination criteria are frequently updated to reflect the current trends. Also, an important factor from the point of view of our research was that many particular RE/BA techniques are described in these sources. We decided not to rely on one certification scheme only, but to analyze several ones, compare them with respect to the recommended techniques and to develop a unified list of such techniques based on all analyzed sources. We selected certification approaches established by International Requirements Engineering Board (IREB), Requirements Engineering Qualifications Board (REQB) and International Institute of Business Analysis (IIBA). The following documents describing these 3 approaches were used:

- IIBA Business Analysis Body of Knowledge (BABOK) Guide ver. 2 [12],

- IREB CPRE Foundation level syllabus ver. 2.2 [16],

- IREB CPRE Elicitation \& Consolidation, Advanced Level syllabus ver. 1.0 [14],

- REQB CPRE Foundation Level syllabus ver. 2.1 [32], 
- REQB CPRE Advanced Level Requirements Manager ver. 1.0 [30].

We used the documents which were available at the time, as e.g. IREB CPRE Advanced Level Requirements Modeling syllabus [15] was published later and other documents were updated (IREB CPRE Foundation Level syllabus ver. 2.2.2 [17], REQB CPRE Advanced Level Requirements Manager ver. 2.0 [31]). As for BABOK, its current version (3) was published when our work was already in progress (and the standard was not immediately available to us), so we decided to proceed with BABOK 2. Of course, our comparison of three approaches could be revised to reflect all these updates, but in the interview-based study (sections 3.2 - 3.4) we used techniques extracted from particular versions of documents, so we do not introduce such changes to this paper for consistency sake. It is also worth to mention that in 2017 IREB and REQB announced their plan to merge and integrate their certification programmes under IREB's brand [19]. As the comparison of both approaches presented in this paper shows differences with respect to decomposition of RE process and to the recommended techniques, an interesting question arises about the final outcome of such unification efforts.

Each of abovementioned three sources has a different scope and introduces its own decomposition into key areas or activities. They are shown in Figure 2, with distinction between core areas related to requirements development and others e.g. requirements management, quality assurance or competency models. IREB and REQB both focus on RE processes only and have similar process definitions (the most important difference is that REQB distinguishes Requirements Analysis and Requirements Specification, while IREB includes both in a single area of Requirements Documentation). BABOK explicitly addresses a wider scope of Business Analysis, which includes not only RE activities, but also others e.g. business process improvements or facilitating business change. BABOK's so called Knowledge Areas depicted in Figure 2, significantly differ from areas/activities defined in two other sources.

To provide a uniform approach, we had to decide how to define key requirements development areas for our study. We decided to use areas defined in [9][40]: Requirements Elicitation, Requirements Analysis, Requirements Specification and Requirements Validation. All techniques found in sources were mapped to these areas (which was relatively easy for REQB and IREB, but more difficult for BABOK). As mentioned before, Requirements Management and supporting activities were excluded from our study.

All the documents were reviewed to identify particular RE/BA techniques. This task was not as straightforward as it may appear. In BABOK most of techniques are explicitly listed and described in separate sections, but others e.g. RACI Matrix are not included in the list, only mentioned in the text. The other two sources do not list techniques in such explicit manner. REQB enumerates most of them in tables or as bullet items, but some are only mentioned in accompanying description (e.g. several analysis techniques are listed in Table 4 on p. 76 [32], but prototyping is only mentioned on p. 79). Among IREB documents, [16] only enumerates the techniques, while their descriptions are provided in [14], but these two sets of techniques are not exactly the same. Differences can also be spotted between REQB documents e.g. [32] lists and describes 11 elicitation techniques, while [30] omits one of them: use cases. 


\begin{tabular}{|c|c|c|}
\hline $\begin{array}{ll}\text { IREB } \\
-\quad \text { Requirement Elicitation } \\
-\quad \text { Requirement Documentation } \\
-\quad \text { Requirements Validation and } \\
& \text { Negotiation }\end{array}$ & $\begin{array}{ll}\text { REQB } \\
\text { - } & \text { Requirements Elicitation } \\
\text { - } & \text { Requirements Analysis } \\
- & \text { Requirements Specification } \\
\text { - } & \text { Requirements Validation and } \\
& \text { Verification }\end{array}$ & $\begin{array}{ll}\text { IIBA BABOK } \\
\text { - } \quad \text { Business Analysis Planning and } \\
\text { - } & \text { Elicitation } \\
\text { - } & \text { Requirements Management and } \\
& \text { Communication } \\
\text { - } & \text { Enterprise Analysis } \\
\text { - } & \text { Requirements Analysis } \\
\text { - } & \text { Solution Assessment and } \\
& \text { Validation }\end{array}$ \\
\hline - Requirements Management & $\begin{array}{l}\text { - } \quad \text { Traceability of Requirements } \\
\text { - } \quad \text { Configuration and Change } \\
\text { - } \quad \text { Quality Assurance }\end{array}$ & - Underlying Competencies \\
\hline
\end{tabular}

Figure 2. Main RE/BA areas defined in analyzed sources.

The review of the sources was not just about extracting names for each technique mentioned in the text - we aimed at developing a unified list of techniques based on 3 sources. It required several actions and decisions to be made. The first and easiest issue were language differences - quite often similar techniques are given different names e.g. Observation (BABOK) and Field Observation (REQB and IREB); Functional Perspective (IREB), Functional Decomposition (BABOK) and Logical Analysis including Functional Decomposition (REQB). Sometimes however, the difference was not just about names e.g. Document Analysis (BABOK) and System Archaeology (IREB) look similar, but the latter includes analysis of existing system code, while the former does not explicitly mention it and is limited to available documentation.

Another issue was to decide whether some variants of a more general technique should be recognized as separate techniques. For example, Brainstorming is listed as one of elicitation techniques both in BABOK and REQB, while IREB provides several variants of brainstorming and creativity techniques e.g. Method 6-3-5 or 6 Thinking Hats. A similar situation is about reviews because different sources explicitly mention various kinds of this technique (peer review, technical review, informal review etc.). There is no space to describe each decision we had to make, but in general we tended to merge very detailed variants into one (e.g. all the variants listed above became Review), but we were careful not to step too far (e.g. we distinguish Scenarios and Use cases).

The resulting sets of techniques and their traceability to sources are shown in Table 1 (elicitation techniques), Table 2 (analysis techniques) and Table 3 (validation techniques). Minor changes have been introduced to the results previously published ([27]) as result of reconsidering techniques' assignment to RE/BA areas. 
Table 1. Comparison of requirements elicitation techniques in sources.

\begin{tabular}{|l|c|c|c|}
\hline Technique & IREB & REQB & IIBA \\
\hline Apprenticing & $\mathrm{X}$ & $\mathrm{X}$ & \\
\hline Benchmarking & & & $\mathrm{X}$ \\
\hline Brainstorming & $\mathrm{X}$ & $\mathrm{X}$ & $\mathrm{X}$ \\
\hline Context modeling & $\mathrm{X}$ & $\mathrm{X}$ & $\mathrm{X}$ \\
\hline Contextual inquiry & $\mathrm{X}$ & & \\
\hline Customer representative on site & & $\mathrm{X}$ & \\
\hline Decision analysis & & & $\mathrm{X}$ \\
\hline Document analysis & $\mathrm{X}$ & $\mathrm{X}$ & $\mathrm{X}$ \\
\hline Elevator pitch & $\mathrm{X}$ & & \\
\hline Focus groups & & & $\mathrm{X}$ \\
\hline Functional decomposition & $\mathrm{X}$ & $\mathrm{X}$ & $\mathrm{X}$ \\
\hline Interface analysis & & & $\mathrm{X}$ \\
\hline Interviews & $\mathrm{X}$ & $\mathrm{X}$ & $\mathrm{X}$ \\
\hline Observation & $\mathrm{X}$ & $\mathrm{X}$ & $\mathrm{X}$ \\
\hline Organization modeling & & & $\mathrm{X}$ \\
\hline Persona & $\mathrm{X}$ & $\mathrm{X}$ & \\
\hline Perspective-based reading & $\mathrm{X}$ & & \\
\hline Problem tracking & & & $\mathrm{X}$ \\
\hline Process modeling & $\mathrm{X}$ & $\mathrm{X}$ & $\mathrm{X}$ \\
\hline Prototyping & $\mathrm{X}$ & $\mathrm{X}$ & $\mathrm{X}$ \\
\hline Questionnaires / surveys & $\mathrm{X}$ & $\mathrm{X}$ & $\mathrm{X}$ \\
\hline RACI matrix & & & $\mathrm{X}$ \\
\hline Reuse of requirements & $\mathrm{X}$ & $\mathrm{X}$ & $\mathrm{X}$ \\
\hline Scenarios & $\mathrm{X}$ & & $\mathrm{X}$ \\
\hline Self-recording & $\mathrm{X}$ & $\mathrm{X}$ & $\mathrm{X}$ \\
\hline Stakeholder map & $\mathrm{X}$ & & \\
\hline Storyboards & $\mathrm{X}$ & $\mathrm{X}$ & $\mathrm{X}$ \\
\hline Use cases & & \\
\hline User stories & & $\mathrm{X}$ \\
\hline User-Centered Design & & \\
\hline Workshop & & \\
\hline
\end{tabular}


Table 2. Comparison of requirements analysis techniques in sources.

\begin{tabular}{|l|c|c|c|}
\hline Technique & IREB & REQB & IIBA \\
\hline Baseline and satellite stakeholders & & $\mathrm{X}$ & \\
\hline Business rules analysis & & & $\mathrm{X}$ \\
\hline Cost-value prioritization & $\mathrm{X}$ & $\mathrm{X}$ & \\
\hline Data flow diagram & $\mathrm{X}$ & $\mathrm{X}$ & $\mathrm{X}$ \\
\hline Data modeling & $\mathrm{X}$ & $\mathrm{X}$ & $\mathrm{X}$ \\
\hline Decision analysis & & $\mathrm{X}$ & $\mathrm{X}$ \\
\hline Functional decomposition & & $\mathrm{X}$ & $\mathrm{X}$ \\
\hline MoScoW prioritization & & & $\mathrm{X}$ \\
\hline Organizational modeling & $\mathrm{X}$ & $\mathrm{X}$ & $\mathrm{X}$ \\
\hline Process modeling & & $\mathrm{X}$ & \\
\hline Requirements diagram & & & $\mathrm{X}$ \\
\hline Scope modeling & & $\mathrm{X}$ & $\mathrm{X}$ \\
\hline Sequence diagram & & $\mathrm{X}$ & $\mathrm{X}$ \\
\hline Simple scale prioritization & $\mathrm{X}$ & $\mathrm{X}$ & $\mathrm{X}$ \\
\hline State modeling & & & $\mathrm{X}$ \\
\hline Timeboxing / Budgeting & & $\mathrm{X}$ & $\mathrm{X}$ \\
\hline Use cases & & & $\mathrm{X}$ \\
\hline User stories & $\mathrm{X}$ & & $\mathrm{X}$ \\
\hline Voting & &
\end{tabular}

Requirements specification area differs from the others. First of all, this area is interpreted in different ways by various sources - it can concern particular documenting techniques (diagrams, notations, modeling languages) or contents of requirements specification documents. We decided to choose the second option - REQB's "Requirements Specification" area concerns SRS contents only, while diagrams and notations are listed as "Requirements Analysis" techniques, IREB distinguishes two sub-areas of Requirements Documentation one focusing on notations, the other on SRS contents. Another issue is that neither of sources provides details on Software Requirements Specification (SRS) contents. BABOK only enumerates several kinds of specification documents, IREB refers to IEEE 29148:2011 [20], while REQB to older standards (IEEE 830:1998 [10], ISO/IEEE 1233:1998 [11]). Thus, comparison of our 3 sources in this area is de facto a comparison between IEEE standards with respect to SRS contents and requirements categories. Our conclusion of such comparison was that IEEE 29148:2011 includes specification document sections listed in the older standards and provides additional ones (as it introduces several documents of different abstraction levels: Stakeholder Requirements Specification, System Requirements Specification and Software Requirements Specification). As result we developed a list of sections, which (according to IEEE 29148:2011) should be used to document requirements. We do not provide such list here, as the standard is copyrighted, the readers more interested in details are referred to [20]. For the sake of brevity we use the expression "RE/BA techniques", when referring to our findings from step 1 described here, but it should be stressed that in case of requirements specification area, they are not really techniques, but rather information items that can be included in specification documents. 
Table 3. Comparison of requirements validation techniques in sources.

\begin{tabular}{|l|c|c|c|}
\hline Technique & IREB & REQB & IIBA \\
\hline Acceptance and evaluation criteria definition & & & $\mathrm{X}$ \\
\hline Checklist & $\mathrm{X}$ & $\mathrm{X}$ & $\mathrm{X}$ \\
\hline Inspection & $\mathrm{X}$ & $\mathrm{X}$ & $\mathrm{X}$ \\
\hline Prototyping & $\mathrm{X}$ & $\mathrm{X}$ & $\mathrm{X}$ \\
\hline Review & $\mathrm{X}$ & $\mathrm{X}$ & $\mathrm{X}$ \\
\hline Root cause analysis & & & $\mathrm{X}$ \\
\hline Walkthrough & $\mathrm{X}$ & $\mathrm{X}$ & $\mathrm{X}$ \\
\hline
\end{tabular}

For each item of the resulting unified set of techniques, an analysis of their applicability according to sources (advantages, limitations) was made. Information from all sources which included a given technique was compiled into a more comprehensive description of its applicability. An example regarding Brainstorming technique is given below (a traceability of particular statements to their source documents is provided):

Technique: Brainstorming

Description: Brainstorming is a technique intended to produce a broad or diverse set of options [12]. It is best applied in a group as it draws on the experience and creativity of all members of the group [12]. The suggested size of the group is 5-10 [14] (alternatively: 6-8 [12]).The meeting (brainstorming session) should last about 20 minutes [14]. A moderator is assigned to ensure the proper conduct of the method [14]. During the brainstorming session, the participants submit ideas and concepts regarding a given problem [32]. Brainstorming works by focusing on a topic or problem and then coming up with many possible solutions to it [12]. The crucial point is the separation of generating the ideas from analyzing the ideas [14]. The technique is based on the group dynamic effect that the participants inspire each other and therefore come up with new ideas [14]. To heighten creativity, participants are encouraged to use new ways of looking at things and free associate in any direction [12]. It is a commonly used technique to obtain requirements related to areas of an organization's activity or planned system functionality that are new or not well known [32]. Facilitated properly, brainstorming can be fun, engaging and productive [12]. The process of brainstorming includes the following activities [12] [14]:

- Preparation: the aim and area of interest is defined, group members and moderator selected, time limit set and criteria for evaluating ideas are determined.

- Brainstorming session: participants share ideas (no criticism or discussion is allowed), the moderator gathers the ideas and records them in a way visible to all participants and encourages participants' creativity.

- Wrap-up: a condensed list of ideas is prepared (no duplicates) and evaluation of ideas (with respect to criteria determined during Preparation) takes place.

\section{Advantages:}

- $\quad$ Enables creative thinking and elicitation of many ideas [12]

- Applicable in a short time and with low cost [32] 
- $\quad$ Can reduce tension between members of the group [12]

\section{Limitations:}

- Depends on participants' creativity and willingness, can be difficult with nonmotivated participants [12] [32]

- $\quad$ Can be negatively affected by organizational and interpersonal politics [12]

- $\quad$ Can be difficult to apply in distributed teams [32]

- Group participants must agree on delayed evaluation and hold back any criticism or comments during brainstorming session, which is not easy to ensure [12]

\subsection{Step 2 - Identification of Problems}

Step 2 aimed at identification of problems encountered in business analysts' professional experience. It started with gathering a group of analysts and arranging interviews.

The participating analysts represented two companies (4 analysts from each one). For the sake of confidentiality we will use names Company A and Company B. Company A employs about 140 staff and specializes in outsourcing of IT services and development of web-based solutions for business. Projects are mostly run using agile methodology, by relatively small teams (4-10 people per project). Company B employs over 350 people and is mainly active in the financial industry, but includes its own IT department (30 people) responsible for IT infrastructure, data storage and software development. Software projects are managed using various approaches and methodologies e.g. waterfall model, V model, agile - depending on project's size and other constraints. Project teams vary greatly (from 3 to 20 people) and some projects, especially maintenance-oriented ones, are rather shortstaffed.

These two companies were selected because of their different profiles. A number of business analysts from both companies were initially identified as potential interviewees. Only the employees with designated job position as business analyst and experience in this field were approached. They were contacted through the network of professional contacts, by approaching them in person or via email, explaining the rationale and scope of the study and asking them to participate. Initially more people were asked, but some either refused to participate or proved uncooperative. The participation was entirely voluntary, the study was not e.g. endorsed by the management.

The final group consisted of 8 people with a substantial experience in the field of business analysis:

- 5 participants with more than 5 years of experience;

- 3 participants with the experience between 2 and 5 years.

Each of 8 participants was individually asked about the problems encountered in his/her job experience using an open question: "As an analyst, what problems do you encounter most often in your work?". The participant was supposed to list as many problems as he/she could think of. Also, he/she was asked to evaluate each of mentioned problems with respect to the frequency of its occurrence. The frequency was measured using an ordinal scale (1 least frequent, 10 - most frequent). Answers were collected within two weeks by e-mail. 
After collecting all answers, a "data processing” activity was conducted. Answers for an open question usually require some clarification and this case was no exception. In particular, it was essential to merge the answers which reported the same problem, but using different natural language expressions.

For example, one interviewee listed as problems: "Functional changes after user acceptance tests" and "Additional requirements issued during customer-analyst meetings, compared to already agreed and prioritized requirements", while another one reported "Changes of functionality during the whole project". These 3 sentences were merged into a more encompassing one: "Changing requirements".

In all such cases the problem was only listed once (preferably under the most meaningful name), but with a sum of all frequency scores. Sometimes a clarification and/or refinement was required when we had doubts about the meaning of a particular problem or the problem was too generic (e.g. "communication problems"). In such cases, a participant was contacted to clarify doubts and/or provide additional details. Also, the problems that turned out not directly related to RE/BA (but to e.g. company politics or interpersonal issues instead) were rejected.

Next, a classification of problems into the particular areas (elicitation, analysis, specification, validation) took place. A given problem could be assigned to one or more areas (e.g. "Lack of stakeholders' commitment" problem was assigned to elicitation and validation areas, while "Changing requirements" problem was considered to affect all four areas). Four problems were revealed to belong to requirements management area (excluded from study scope) and were omitted from further analysis.

Some reported problems were quite surprising to us, because their source turned out to be the analyst, not the customer, market situation or other independent factor. For example: "An analyst prematurely assumes that he/she understands stakeholder's requirements" (resulting in lack of commitment to pursue the issue further), or "An analyst skips recording requirements to reduce project's scope and related effort". At first, we intended to exclude such problems from the further analysis, as it appeared that they stem from analyst's negligence. If so, no advanced RE/BA technique, but rather a more responsible approach of the analyst to his/her duties is required. However, follow-up contacts and requests for explanation revealed that the interviewees encountered such problems working together with their fellow analysts (often less experienced ones) and believed that application of a technique capable of preventing such errors would be beneficial. Finally, we decided to treat those problems like all others and to find appropriate solutions to them.

The final list of problems reported by interviewees included 49 items, together with 86 frequency scores. Out of them, we selected 28 problems which are presented in Table 4, with their frequency scores and areas of concern (elicitation, analysis, specification, validation). Among these 28 were the problems with highest frequency scores. Some others were in turn selected to cover various causal factors (project constraints, stakeholders, developers, also business analysts themselves). It is visible from the summary scores (and the ratio: 49 items - 86 scores) that the sets of problems stated by particular interviewees differ from each other. This is obviously the result of an "ad hoc" manner of identifying problems, which however was intentional - we wanted not to restrict the potential outcome by e.g. providing a checklist of problems. We assumed, that if a particular issue is really a frequent problem in analyst's working activities, then he/she will remember about it and include it in the list. 
Table 4. Results of interviews - problems with the highest summary scores.

\begin{tabular}{|c|c|c|c|c|c|c|}
\hline$\#$ & Problem & Score & $\mathbf{E}$ & A & $\mathbf{S}$ & $\mathbf{V}$ \\
\hline 1 & Changing requirements & 30 & $\mathrm{X}$ & $\mathrm{X}$ & $\mathrm{X}$ & $\mathrm{X}$ \\
\hline 2 & Too short deadlines to complete BA & 30 & $\mathrm{X}$ & $\mathrm{X}$ & $\mathrm{X}$ & $\mathrm{X}$ \\
\hline 3 & $\begin{array}{l}\text { Lack of the authorized stakeholders i.e. capable } \\
\text { of making decisions }\end{array}$ & 30 & $\mathrm{X}$ & & & \\
\hline 4 & $\begin{array}{l}\text { The stakeholders are unable to express their } \\
\text { needs/requirements }\end{array}$ & 29 & $\mathrm{X}$ & & & \\
\hline 5 & Analyzing undocumented existing system & 28 & $\mathrm{X}$ & $\mathrm{X}$ & & \\
\hline 6 & Lack of stakeholders' commitment & 19 & $\mathrm{X}$ & & & $\mathrm{X}$ \\
\hline 7 & $\begin{array}{l}\text { The stakeholders completely do not know what } \\
\text { they want }\end{array}$ & 15 & $\mathrm{X}$ & & & \\
\hline 8 & $\begin{array}{l}\text { The stakeholders express requirements which are } \\
\text { outside system's scope }\end{array}$ & 14 & $\mathrm{X}$ & & & \\
\hline 9 & Failure to identify an essential stakeholder & 13 & $\mathrm{X}$ & & & \\
\hline 10 & $\begin{array}{l}\text { Low quality of specified requirements (e.g. } \\
\text { incomplete, too generic) }\end{array}$ & 12 & & & $\mathrm{X}$ & \\
\hline 11 & $\begin{array}{l}\text { The stakeholders avoid participating in } \\
\text { verification and validation activities }\end{array}$ & 12 & & & & $\mathrm{X}$ \\
\hline 12 & Failure to identify an essential requirement & 11 & $\mathrm{X}$ & & & \\
\hline 13 & $\begin{array}{l}\text { Limited access to an existing system treated as } \\
\text { source of requirements }\end{array}$ & 9 & $\mathrm{X}$ & & & \\
\hline 14 & $\begin{array}{l}\text { An analyst derives a different interpretation of a } \\
\text { requirement than stakeholder }\end{array}$ & 8 & $\mathrm{X}$ & & & \\
\hline 15 & $\begin{array}{l}\text { Terminology differences causing communication } \\
\text { gaps }\end{array}$ & 8 & $\mathrm{X}$ & $\mathrm{X}$ & $\mathrm{X}$ & $\mathrm{X}$ \\
\hline 16 & $\begin{array}{l}\text { Requirements not specified in measurable/ } \\
\text { verifiable form }\end{array}$ & 8 & & & $\mathrm{X}$ & $\mathrm{X}$ \\
\hline 17 & No clearly defined system scope & 8 & $\mathrm{X}$ & $\mathrm{X}$ & & $\mathrm{X}$ \\
\hline 18 & $\begin{array}{l}\text { An analyst skips recording requirements to } \\
\text { reduce project's scope and related effort }\end{array}$ & 7 & $\mathrm{X}$ & & & \\
\hline 19 & Non-functional requirements are not considered & 7 & $\mathrm{X}$ & $\mathrm{X}$ & & \\
\hline 20 & No priorities assigned to requirements & 7 & & $\mathrm{X}$ & & \\
\hline 21 & No explicitly agreed SRS template available & 6 & & & $\mathrm{X}$ & \\
\hline 22 & $\begin{array}{l}\text { A stakeholder describes a technical solution } \\
\text { instead of a requirement }\end{array}$ & 6 & $\mathrm{X}$ & & & \\
\hline 23 & No acceptance criteria defined & 6 & & & & $\mathrm{X}$ \\
\hline 24 & $\begin{array}{l}\text { An analyst prematurely assumes that he/she } \\
\text { understands stakeholder's requirements }\end{array}$ & 5 & $\mathrm{X}$ & & & \\
\hline 25 & $\begin{array}{l}\text { An analyst focuses more on designing system } \\
\text { than on specifying requirements }\end{array}$ & 5 & & $\mathrm{X}$ & $\mathrm{X}$ & \\
\hline 26 & No business goals for a system are defined & 5 & $\mathrm{X}$ & & & \\
\hline 27 & $\begin{array}{l}\text { No explicit specification of system/project } \\
\text { constraints }\end{array}$ & 5 & $\mathrm{X}$ & & & \\
\hline 28 & Hidden assumptions made by an analyst & 5 & $\mathrm{X}$ & $\mathrm{X}$ & $\mathrm{X}$ & \\
\hline
\end{tabular}




\subsection{Step 3 - Solution Proposals}

In step 3, the analysis of gathered problems and available RE/BA techniques was planned to propose solution to each problem. However, because of such a significant number of reported problems, we decided to select a subset of them (28 out of 49) and to exclude the remaining ones (as mentioned in Section 3.2).

The search for appropriate solutions to problems was based on the guidelines for applying each particular technique (description, pros and cons) compiled from 3 sources described in section 3.1. The process was iterative, first several candidate techniques were considered, then selection of the most promising solutions (up to 3) was made. The process was based on analysis of issues expressed in natural language, therefore it is hardly possible to describe it in an algorithmic form, with precise decision criteria. Solution proposals prepared in this step are presented later in Table 5, which also includes validation results.

\subsection{Step 4 - Validation}

Step 4 focused on validation - finding out whether the solutions developed using guidelines from recognized sources are useful in practice from the point of view of a business analyst. Interviews were chosen as the method of validation. Two analysts from the previous group of 8 were contacted. They were among the most active participants who contributed the highest numbers of problems. Also, they worked for different companies (A and B) and held different positions (A - senior analyst, B - junior analyst). Validation interviews were arranged separately with each analyst. During the interview each of 28 considered problems was discussed using the following scheme:

1. The researcher asked the interviewed analyst to come up with proposal of solutions to a given problem.

2. The researcher revealed his own proposal developed in step 3 .

3. A comparison of the proposals by both participants took place, followed by a discussion to reach a consensus.

In some cases the proposals of the researcher and the interviewee were exactly the same, so no discussion was necessary, but mostly there were at least partial differences. Incidentally, the interviewee admitted he had no idea which technique to apply for a given problem (literally 2 cases). The outcome of the discussion could be either:

1. The interviewee admitted that the proposals of the researcher are a better solution (or at least not worse - quite often the conclusion was that different techniques can be used as equivalent solutions).

2. The interviewee convinced the researcher that his proposal should be changed or at least extended by applying additional technique.

Depending on the outcomes of the interviews, the following course of action could be taken to incorporate validation results into the proposed set of solutions:

1. No change - validation confirmed that the proposal is sound, no counter-proposals were issued by the interviewees (12 problems). 
2. Extension - another technique was added as part of the solution, especially if it reinforced the techniques already included (14 problems).

3. Alteration - the initial solution proposal was modified by substituting one or more techniques with others, as suggested by one or both interviewees (2 problems).

The researcher took detailed notes documenting the discussions and afterwards summarized the outcomes for each of the problems. Three examples (one for each of three possible outcomes) are presented below.

Name of the problem: Lack of the authorized stakeholders i.e. capable of making decisions) (problem no. 3)

Researcher: An analyst can encounter situations when he/she is not able to determine authorized stakeholders (or replacements of such stakeholders in case of their temporary absence). Preparation of stakeholder map in early phase of requirements engineering can prove helpful. Stakeholder map allows to identify interdependencies between stakeholders and their areas/levels of authority. An alternative technique is RACI matrix, which explicitly represents particular types of responsibility (responsible, accountable, consulted, informed) for each stakeholder.

Analyst A: The initial idea of the first analyst was to use prototyping to prepare several alternative proposals and not waste time waiting for authorized stakeholder to become available. During the discussion, he admitted that he considered the problem from different perspective than the researcher and researcher's proposals addresses the more essential aspect. He still claimed that prototyping could be useful to present alternative solutions to the decision-maker, but first and foremost such person has to be identified.

Analyst B: A first, an intuitive answer from the second analyst was that in such situations the problem is delegated to the supervisor of the missing stakeholder. To determine who this supervisor is, the interviewed analyst would check appropriate section of System Requirements Specification. After the researcher presented his proposals, the analyst agreed that such techniques are adequate solutions to this problem and in general to describe stakeholders in SRS document.

Conclusion: Despite the fact that each analyst initially came up with other proposals, a consensus was reached that researcher's proposals should be recommended as solutions to this problem.

Outcome: No change

Name of the problem: The stakeholders avoid participating in verification and validation activities (problem no. 11)

Researcher: The most effective technique to ensure verification and validation is inspection, as it provides several mechanisms to ensure involvement of participants (e.g. detection mechanisms, inspection meeting). Inspection's drawback is that it requires significant effort and is time-consuming, but in case of problematic validation it can still be worth considering.

Analyst A: The first analysts answered that facing such problem, he would conduct an inspection of requirements document, together with an authorized stakeholder, to get requirements sign-off or a list of issues to be corrected. 
Analyst B: The second analyst's preferred approach was to use prototyping to provide the stakeholders with something more convenient than a document. He argued that, from his experience, stakeholders are usually not willing to conduct inspection of the full SRS document. Instead they expect to be provided with a shorter summary, so inspection is possible in reduced scope only.

\section{Conclusion:}

The researcher agreed that prototypes seem to be an adequate solution here. However, due to the fact that the first analyst chose inspections and to the reasoning that it is unlikely that prototypes would the only requirements representation, inspection remained as a solution to this problem as well.

Outcome: Extension

Name of the problem: Lack of stakeholders' commitment (problem no. 6)

Researcher: Two different solutions can be applied. A more "friendly" approach is to facilitate workshops or brainstorming and therefore to stimulate the stakeholders to be more active and creative in requirements elicitation. These techniques were selected, because they are generally known to stimulate creativity and involve participants. An alternative approach results in a more confrontational way and includes usage of the stakeholders map technique. The map enables the analyst to understand the organizational hierarchy of a company or project and to contact a superior of an uncooperative stakeholders who can deal with them or find a replacement.

Analyst A: The first analyst was inclined to apply workshops or brainstorming with an emphasis on choosing the ones with a more attractive form. He said that an approach which includes a creative way of eliciting requirements and is considered fun would be more profitable than a standard "boring" meeting. During the discussion, the researcher presented his solutions including the "unpleasant way" with using a stakeholders map, but the analyst disagreed with that approach.

Analyst B: The second analyst also proposed workshops and brainstorming, but he also suggested using prototypes as a way to capture stakeholders' attention and as result effectively elicit requirements. After hearing researchers' proposals, the analyst agreed that they are suitable.

Conclusion: In all 3 cases, the preferable solution was to stimulate stakeholders' initiative by using creative techniques like workshops, brainstorming and prototyping. The researcher decided to add prototyping to the short list of suitable solutions to this problem. On the other hand, the idea of using stakeholders map was discarded as a result of validation. The researcher was convinced by the argument of Analyst A, that it could result in a negative attitude and harm relationships between the project team and the stakeholders.

Outcome: Alteration

The validated solutions to problems are presented in Table 5. The table also shows changes resulting from validation - the techniques added to the initial proposal are distinguished by underline (e.g. Prototyping) and the ones removed from it by strikethrough (e.g. Stakeholder map). Additional comments e.g. how to apply a given technique are given in italics. 
Table 5. Techniques assigned as solutions.

\begin{tabular}{|c|c|c|}
\hline$\#$ & Problem & $\begin{array}{l}\text { Techniques assigned } \\
\text { (after validation) }\end{array}$ \\
\hline 1 & Changing requirements & $\begin{array}{l}\text { Requirement diagram, Cost-value } \\
\text { prioritization, Prototyping }\end{array}$ \\
\hline 2 & Too short deadlines to complete BA & $\begin{array}{l}\text { Timeboxing/Budgeting, MoSCoW } \\
\text { prioritization }\end{array}$ \\
\hline 3 & $\begin{array}{l}\text { Lack of the authorized stakeholders i.e. } \\
\text { capable of making decisions }\end{array}$ & Stakeholder map, RACI matrix \\
\hline 4 & $\begin{array}{l}\text { The stakeholders are unable to express their } \\
\text { needs/requirements }\end{array}$ & Observation \\
\hline 5 & Analyzing undocumented existing system & $\begin{array}{l}\text { Document analysis, Observation, } \\
\text { "Stakeholders" section of SRS }\end{array}$ \\
\hline 6 & Lack of stakeholders' commitment & $\begin{array}{l}\text { Stakeholder map, Brainstorming, } \\
\text { Workshop, Prototyping }\end{array}$ \\
\hline 7 & $\begin{array}{l}\text { The stakeholders completely do not know } \\
\text { what they want }\end{array}$ & Brainstorming, Interviews, Workshop \\
\hline 8 & $\begin{array}{l}\text { Stakeholders express requirements which } \\
\text { are outside system's scope }\end{array}$ & Scope modeling, Process modeling \\
\hline 9 & Failure to identify an essential stakeholder & $\begin{array}{l}\text { Stakeholder map, RACI matrix, } \\
\text { Process modeling }\end{array}$ \\
\hline 10 & $\begin{array}{l}\text { Low quality of specified requirements (e.g. } \\
\text { incomplete, too generic) }\end{array}$ & $\begin{array}{l}\text { "Non-functional requirements" section of } \\
\text { SRS, User stories, Scenarios, } \underline{\text { Process }} \\
\text { modeling }\end{array}$ \\
\hline 11 & $\begin{array}{l}\text { The stakeholders avoid participating in } \\
\text { verification and validation activities }\end{array}$ & Inspection, Prototyping \\
\hline 12 & Failure to identify an essential requirement & $\begin{array}{l}\text { Prototyping, Workshop, State modeling, } \\
\text { Data modeling (conceptual level - business } \\
\underline{\text { classes), Review }}\end{array}$ \\
\hline 13 & $\begin{array}{l}\text { Limited access to an existing system treated } \\
\text { as source of requirements }\end{array}$ & Document Analysis, Apprenticing \\
\hline 14 & $\begin{array}{l}\text { An analyst derives a different interpretation } \\
\text { of a requirement than stakeholder }\end{array}$ & $\begin{array}{l}\text { Interview (unstructured), Prototyping, } \\
\text { Process modeling, Inspection, Observation }\end{array}$ \\
\hline 15 & $\begin{array}{l}\text { Terminology differences causing communi- } \\
\text { cation gaps }\end{array}$ & $\begin{array}{l}\text { "Definitions and acronyms" section of SRS, } \\
\text { Workshop }\end{array}$ \\
\hline 16 & $\begin{array}{l}\text { Requirements not specified in measurable/ } \\
\text { verifiable form }\end{array}$ & $\begin{array}{l}\text { "Non-functional requirements" section of } \\
\text { SRS, Acceptance and evaluation criteria } \\
\text { definition, Interview }\end{array}$ \\
\hline 17 & No clearly defined system scope & Scope Modeling, Interviews \\
\hline
\end{tabular}




\begin{tabular}{|c|c|c|}
\hline 18 & $\begin{array}{l}\text { An analyst skips recording requirements to } \\
\text { reduce project's scope and related effort }\end{array}$ & $\begin{array}{l}\text { MoSCoW prioritization, Cost-value } \\
\text { prioritization }\end{array}$ \\
\hline 19 & $\begin{array}{l}\text { Non-functional requirements are not } \\
\text { considered }\end{array}$ & $\begin{array}{l}\text { Interview (structured), Workshop, “Non- } \\
\text { functional requirements” section of SRS }\end{array}$ \\
\hline 20 & No priorities assigned to requirements & $\begin{array}{l}\text { MoSCoW prioritization, } \\
\text { Timeboxing/Budgeting, Simple scale } \\
\text { prioritization, Workshop }\end{array}$ \\
\hline 21 & $\begin{array}{l}\text { No explicitly agreed SRS template } \\
\text { available }\end{array}$ & $\begin{array}{l}\text { Brainstorming, Workshop (to identify } \\
\text { relevant SRS sections based e.g. on } 29148 \\
\text { std) }\end{array}$ \\
\hline 22 & $\begin{array}{l}\text { A stakeholder describes a technical solution } \\
\text { instead of a requirement }\end{array}$ & $\begin{array}{l}\text { Workshop, Cost-value prioritization (to } \\
\text { identify and evaluate alternatives), } \\
\text { Prototyping, Observation }\end{array}$ \\
\hline 23 & No acceptance criteria defined & $\begin{array}{l}\text { Workshop, “Non-functional requirements" } \\
\text { section of SRS }\end{array}$ \\
\hline 24 & $\begin{array}{l}\text { An analyst prematurely assumes that he/she } \\
\text { understands stakeholder's requirements }\end{array}$ & $\begin{array}{l}\text { Interview (structured only), Prototyping, } \\
\text { Inspection }\end{array}$ \\
\hline 25 & $\begin{array}{l}\text { An analyst focuses more on designing } \\
\text { system than on specifying requirements }\end{array}$ & $\begin{array}{l}\text { Review (by other analysts), Inspection (by } \\
\text { other analysts) }\end{array}$ \\
\hline 26 & No business goals for a system are defined & $\begin{array}{l}\text { Interview, "Business purpose" section of } \\
\text { SRS, "Goal and objective” section of SRS, } \\
\text { Observation }\end{array}$ \\
\hline 27 & $\begin{array}{l}\text { No explicit specification of system/project } \\
\text { constraints }\end{array}$ & "System constraints" section of SRS \\
\hline 28 & Hidden assumptions made by an analyst & $\begin{array}{l}\text { Review / Inspection (by other analysts), } \\
\text { “Assumptions and dependencies” section of } \\
\text { SRS, Prototyping }\end{array}$ \\
\hline
\end{tabular}

\section{Validity Discussion}

A number of validity threats with a possible impact on results of our research study can be identified and should be discussed.

- $\quad$ Representativeness of participants - The possible threat is that participants involved are not representative as industry practitioners and business analysts, especially considering their small number (8 participants). This number was mainly a result of selected research method i.e. interview-based survey, which requires much more effort than e.g. web-based questionnaire survey but also enables gathering more detailed information. Moreover, our participants represented only 2 software companies, which however were chosen because of their different profiles. We also approached only practitioners with at least 2 years of experience as business analysts, so no bias stemming from lack 
of knowledge or experience would be introduced. However, despite all above actions we cannot be completely sure of participants' representativeness.

- $\quad$ Representativeness of RE/BA sources - A number of sources on RE/BA including books, standards and research papers are available. The sources we used to identify RE/BA techniques are not the only ones, as e.g. Project Management Institute's guide [29] was not included. However, our efforts to choose the sources which are general (not domain-specific), up to date and recognized by practitioners (considering numbers of certificates obtained) indicate that this threat was minimized.

- $\quad$ Adequacy of problems reported - Doubts can be raised about problems gathered from survey participants, especially considering the low similarity of problems reported by distinct participants: are they really the most serious ones troubling business analysts in Polish IT industry? We decided to ask open questions about problems because we wanted to avoid suggesting any answers. At hindsight we however admit, that some guidance (e.g. list of potential problems or their categories) could be used here and we cannot dismiss this threat. Also, frequency scores were gathered from a small-N sample, which could rise doubts about their accuracy.

- Subjectivity of assessments - Another potential threat is that the assessments made interviewees about problems' frequencies and applicability of solutions are not objective, but possibly biased by their subjective point of view. This threat has to be accepted, as subjectivity is an integral part of the qualitative research method used in this study.

- Other criteria for techniques selection - RE/BA techniques differ with respect to the required resources (time, cost), expected involvement level of stakeholders as well as skills and competencies required from business analyst to successfully use a given technique. Neither of such aspects was considered in our study, as we solely focused on techniques' applicability to solve problems. However it is hard to assume that such single criterion alone would drive a choice of RE/BA techniques for a particular software project.

- Generalization of results and findings - The reported (rather small-scale) study was designed from the beginning to target Polish IT sector. We do not make any assumptions about whether conditions of business analyst's work in Poland are the same or significantly different than elsewhere - we simply report our results.

\section{Conclusions and Further Work}

The review of the state of the art RE/BA knowledge sources resulted in a large set of recommended RE/BA techniques. A side effect of this work is the observation that apart from the "core" established and well known techniques (like prototyping, questionnaires or observations), the reviewed industrial standards recommend different techniques as tools for business analysts.

The study uncovered a number of problems expressed by a group of business analysts and related to their work activities. For each of frequent problems a solution in the form of one or more RE/BA techniques was proposed. Validation shows that the set of techniques developed by unifying contents of 3 selected sources was sufficient to address each of the 
problems considered. Moreover, the guidelines on applicability of particular techniques compiled from 3 sources allowed to select the right techniques (only 2 out of 28 proposals were rejected by business analysts participating in validation). The substantial number of proposals which were extended with additional techniques as result of validation suggest that the set of available techniques includes many items which can be used interchangeably, as replacements for each other.

A number of results published in this paper can be considered rather unique. No thorough analysis of current industrial standards with respect to RE/BA techniques recommended by them is available, according to the best of our knowledge. Despite the fact, that several surveys on problems encountered in RE/BA industry practice were published, none of them focused on Polish IT industry, but targeted other countries instead. Also, a systematic approach for addressing particular RE/BA problems by identifying most suitable techniques as solutions was not explicitly proposed in any source known to us.

The contribution of our research is addressed to business analysts and other industry practitioners, who can use it to: (1) acquire a compact summary about the contents of industrial standards and certification schemes, especially with respect to RE/BA techniques; (2) consider the use of techniques we identified as a means to address particular problem in case such a problem occurs in real life software project. Our findings however should not be used as a single reason behind techniques' selection as other aspects (e.g. cost, difficulty) should also be considered (as indicated in validity discussion in section 4).

As for future work, we consider reviewing additional sources e.g. PMI Guide, because even if the current set of techniques seems to be "sufficient", more guidelines and hints about which one to apply would be helpful (especially in case of similar techniques). A study involving a larger number of participants and companies (preferably from different countries) is another possible direction of research. Such larger sample would also provide more accurate evaluations of problems' frequency scores and result in a more convincing ranking of problems. Moreover, as our approach of asking open questions about problems proved to have its drawbacks (low similarity of problems reported), it is worth to consider using a combined approach - a list of problems (based on literature analysis) available to the participant, together with the opportunity to report additional problems.

\section{References}

[1] Aoyama M., Nakatani T., Saito S., Suzuki M., Fujita K., Nakazaki H., Suzuki R., A model and architecture of REBOK (Requirements Engineering Body of Knowledge) and its evaluation, Proc. of 17th Asia Pacific Software Engineering Conference, IEEE, 2010, 50-59.

[2] Besrour S., Bin Ab Rahim L., Dominic P., Assessment and evaluation of requirements elicitation techniques using analysis determination requirements framework, In: Proc. of 2014 International Conference on Computer and Information Sciences, 2014, 1-6. 
[3] Bobkowska A., Wyrzykowski K., A model for the activities of business analysts in public administration for the prevention of hidden requirements (in Polish: Model działania analityka biznesowego $\mathrm{w}$ administracji publicznej $\mathrm{w}$ celu przeciwdziałania ukrytym wymaganiom), Roczniki Kolegium Analiz Ekonomicznych/Szkoła Główna Handlowa, 42, 2016, 13-26.

[4] Charette R.N., Why software fails, IEEE Spectrum 42, 9, 2005, 42-49.

[5] Cheng B., Atlee J., Research directions in requirements engineering, In: Proc. of Future of Software Engineering (FOSE 2007), IEEE Computer Society, Washington DC, 2007, 285-303.

[6] Chrabski B., Zmitrowicz K., Requirements engineering in practice (in Polish: Inżynieria wymagań w praktyce), Wydawnictwo Naukowe PWN, Warsaw, 2015.

[7] Davey B., Parker K., Requirements elicitation problems: a literature analysis, Issues in Informing Science and Information Technology, 12, 2015, 71-82.

[8] Firesmith D., Common requirements problems, their negative consequences and the industry best practices to help solve them, Journal of Object Technology, 6, 1, 2007, 17-33.

[9] IEEE, A Guide to Software Engineering Body of Knowledge 3.0, 2014.

[10] IEEE Standard 830-1998, IEEE Recommended Practice for Software Requirements Specifications, 1998.

[11] IEEE Standard 1233-1998, IEEE Guide for Developing System Requirements Specifications, 1998.

[12] International Institute of Business Analysis, A Guide to the Business Analysis Body of Knowledge (BABOK Guide) v2.0, 2009.

[13] International Institute of Business Analysis, IIBA Annual Report 2015, available: http://www.iiba.org/About-IIBA/About-IIBA/iiba-annual-report-2015.aspx [Accessed 12, October, 2017].

[14] International Requirements Engineering Board, IREB CPRE Advanced Level Elicitation and Consolidation syllabus ver. 1.0, 2012.

[15] International Requirements Engineering Board, IREB CPRE Advanced Level Requirements Modeling syllabus ver. 2.2, 2016.

[16] International Requirements Engineering Board, IREB CPRE Foundation Level Syllabus ver. 2.2, 2015.

[17] International Requirements Engineering Board, IREB CPRE Foundation Level syllabus ver. 2.2.2, 2017.

[18] International Requirements Bngineering Board, https://www.ireb.org/en/service/statistics [Accessed 12, October, 2017].

[19] International Requirements Engineering Board, IREB ${ }^{\circledR}$ and REQB ${ }^{\circledR}$ have decided to join forces, https://www.ireb.org/en/service/news-events/ (2017/01/18 news) [Accessed 12, October, 2017]

[20] ISO/IEC/IEEE Standard 29148-2011, Systems and Software Engineering - Life Cycle Processes - Requirements Engineering, 2011.

[21]Jiang L., Eberlein A., Far B., Mousavi M., A methodology for the selection of requirements engineering techniques, Software \& Systems Modeling, 7, 3, 2008, 303328. 
[22] Karlsson L., Dahlstedt Å.G., Regnell B., och Dag J.N., Persson A., Requirements engineering challenges in market-driven software development - an interview study with practitioners, Information and Software Technology, 49, 6, 2007, 588-604.

[23] Khan H., Asghar I., Ghayyur S., Raza M., An empirical study of software requirements verification and validation techniques along their mitigation strategies, Asian Journal of Computer and Information Systems, 3, 03, 2015.

[24] Kheirkhah E., Deraman A., Important factors in selecting requirements engineering techniques, In: Proc. of International Symposium on Information Technology (ITSim 2008), 2008, 1-5.

[25]Liu L., Li T., Peng F., Why requirements engineering fails: A survey report from China, In: Proc. of 18th Requirements Engineering Conference (RE), 2010, 317-322.

[26] Maalem S., Zarour N., Challenge of validation in requirements engineering, Journal of Innovation in Digital Ecosystems, 3, 1, 2016, 15-21.

[27] Marciniak P., Jarzębowicz A., An industrial survey on business analysis problems and solutions, In: Madeyski L., Śmiałek M., Hnatkowska B., Huzar Z. (eds) Software Engineering: Challenges and Solutions, Advances in Intelligent Systems and Computing, vol 504. Springer International Publishing, 2016, 163-176.

[28] Mendez Fernandez D., Wagner S., Kalinowski M., Schekelmann A., Tuzcu A., Conte T., Spinola R., Prikladnicki R., Naming the Pain in Requirements Engineering: Comparing Practices in Brazil and Germany, IEEE Software 32, 5, 2015, 16-23.

[29] Project Management Institute, Business Analysis for Practitioners. A Practice Guide, 2015.

[30] Requirements Engineering Qualifications Board, REQB CPRE Advanced Level Requirements Manager ver. 1.0, 2011.

[31] Requirements Engineering Qualifications Board, REQB CPRE Advanced Level Requirements Manager ver. 2.0, 2015.

[32] Requirements Engineering Qualifications Board, REQB CPRE Foundation Level Syllabus ver. 2.1, 2014.

[33] Requirements Engineering Qualifications Board, http://reqb.org/index.php/aboutreqb/facts-and-figures [Accessed 19, May, 2017].

[34] dos Santos Soares M., Cioquetta D., Analysis of techniques for documenting user requirements, In: Proc. of Computational Science and Its Applications (ICCSA 2012), 2012, 16-28.

[35] Sethia N.K., Pillai A.S., A study on the software requirements elicitation issues - its causes and effects, In: Proc. of World Congress on Information and Communication Technologies, 2013, 245-252.

[36] Solemon B., Sahibuddin S., Ghani A., Requirements engineering problems and practices in software companies: an industrial survey, In: Ślęzak D., Kim, T.H., Kiumi, A., Jiang, T., Verner, J., Abrahão, S. (eds.) Advances in Software Engineering, Communications in Computer and Information Science Vol. 59, Springer Heidelberg, 2009, 70-77.

[37] The Standish Group International, Chaos Report 2014, 2014.

[38] Vestola M., A comparison of nine basic techniques for requirements prioritization, Helsinki University of Technology, Report, 2010. 
[39] Wellsandt S., Hribernik K., Thoben K., Qualitative comparison of requirements elicitation techniques that are used to collect feedback information about product use, In: Proc. of 24th CIRP Design Conference, 2014, 212-217.

[40] Wiegers K., Beatty J., Software Requirements (3rd Edition), Microsoft Press, 2013.

[41] Yousuf M., Asger M., Comparison of various requirements elicitation techniques, International Journal of Computer Applications, 116, 4, 2015.

[42]Zhang Z., Effective requirements development - a comparison of requirements elicitation techniques. In: Software Quality Management XV: Software Quality in the Knowledge Society, British Computer Society, 2007, 225-240.

[43]Żeliński J., Business analysis: organizational modeling in practice (in Polish: Analiza biznesowa: praktyczne modelowanie organizacji), Helion, 2016.

This paper is a revised and extended version of work originally presented at the 18th KKIO Software Engineering Conference, 15-17 September 2016, Wroclaw, Poland

Received 31.05.2017, Accepted. 21.09.2017 